2009-3

\title{
Families and Childhood Cancer: An Exploration of the Observations of a Pediatric Oncology Treatment Team
}

Amanda Douglas Harrington

Texas Tech University

Thomas G. Kimball

Texas Tech University

Roy A. Bean

Brigham Young University - Provo, roy_bean@byu.edu

Follow this and additional works at: https://scholarsarchive.byu.edu/facpub

Part of the Other Social and Behavioral Sciences Commons

\section{Original Publication Citation}

*Harrington, A. D., Kimball, T. G., \& Bean, R. A. (2009). Families and childhood cancer: An exploration of the experience of a pediatric oncology treatment team. Families, Systems \& Health: The Journal of Collaborative Family Health Care, 27, 16-27.

\section{BYU ScholarsArchive Citation}

Harrington, Amanda Douglas; Kimball, Thomas G.; and Bean, Roy A., "Families and Childhood Cancer: An Exploration of the Observations of a Pediatric Oncology Treatment Team" (2009). Faculty Publications. 5054.

https://scholarsarchive.byu.edu/facpub/5054

This Peer-Reviewed Article is brought to you for free and open access by BYU ScholarsArchive. It has been accepted for inclusion in Faculty Publications by an authorized administrator of BYU ScholarsArchive. For more information, please contact ellen_amatangelo@byu.edu. 


\title{
Families and Childhood Cancer: An Exploration of the Observations of a Pediatric Oncology Treatment Team
}

\author{
Amanda Douglas Harrington, MS \\ Thomas G. Kimball, PhD \\ ROY A. BEAN, PHD
}

The authors propose that families facing childhood cancer inadvertently become part of a distinct cultural group. To better train clinicians working with these families, this study was conducted as a phenomenological exploration of the common experiences of those who work with, and participate in, this "culture of cancer" (i.e., members of a pediatric oncology treatment team that includes medical family therapists). Two primary themes emerged from the data: culture of change and relationships. A qualitative description of medical family therapists as part of the treatment team was also developed. Insight into this culture and recommendations for family therapists working in this area of practice are provided.

Keywords: family therapy, childhood cancer, therapist competence

Amanda Douglas Harrington, PhD candidate, Department of Applied and Professional Studies, Texas Tech University; Thomas G. Kimball, $\mathrm{PhD}$, Center for the Study of Addiction and Recovery, Texas Tech University; Roy A. Bean, PhD, College of Family, Home and Social Sciences, Brigham Young University.

Correspondence concerning this article should be addressed to Thomas G. Kimball, PhD, Center for the Study of Addiction and Recovery, College of Human Sciences, Texas Tech University, Box 41210, Lubbock, TX 79409-1210. E-mail: thomas.kimball@ttu.edu
Tn marriage and family therapy, as well as in other counseling disciplines, there has been a push for relevant and competent approaches to the treatment of specific cultural groups (Kim, Bean, \& Harper, 2004; Sue, Arredondo, \& McDavis, 1992; Sue \& Sue, 2003). Typically framed as a function of ethnic, racial, or religious characteristics, culture contextualizes family dynamics and the associated interactions between therapists and family members. We suggest that culture may transcend ethnicity and race and that other sociodemographic groupings can also be included in its discussion and definition. For instance, the worldview held by families, individuals, and communities can be informed by their experiences of trauma or other pervasive, all-consuming problems such as war, natural disaster, or chronic illness (Morris, 2000). This overarching and collective perspective can be seen as an approximation of the shared culture of a group in that it provides a framework for interpersonal relationships in the family and for interactions with larger systems (e.g., school, work, religious, medical, and legal institutions).

In accordance with this, it is our belief that most families who experience the diagnosis of a child with cancer become participating members in the "culture of childhood cancer." As such, they become 
part of a cultural group with its own unique terminology, traditional practices, rites of passage, and individual- and family-focused demands. Robinson, Carroll, and Watson (2005) referred to this experience in terms of the "old world" that existed before diagnosis and the "cancerdominated world" that is experienced postdiagnosis. They suggested that a family's ability to cope is connected to its ability to navigate this transition. In most cases, families must adapt quickly and learn to function within the culture to survive emotionally and, sometimes, physically. Given the challenges of adapting and surviving, family members can be considered at risk for secondary trauma, poor treatment adherence, problematic functioning, and other complications. As a result, medical family therapists (MedFTs) who are members of this culture must reach a level of clinical competence to help these families adapt to their new cultural grouping. Although several books have been written addressing the impact of ethnic and racial culture on cancer treatment (e.g., Dowell, Copeland, \& van Eys, 1987; Moore \& Spiegel, 2004), it is our contention that MedFTs and other clinicians can consider culture of childhood cancer an appropriate conceptual term, given the omnipresent nature of this illness and its near-total impact on individuals and families.

Our goal in this article is to expand the conceptual and empirical knowledge base associated with this specific diseaserelated group. We present pertinent information regarding therapist competence, along with the results of an effort to create a qualitative description of the common experiences of those who are part of the culture of childhood cancer (i.e., members of a pediatric oncology treatment team).

\section{LITERATURE REVIEW}

Over the past 2 decades, numerous authors have called for culturally competent therapy approaches to treating families; however, only a small number have pro- vided organized approaches for researchers and therapists to follow in meeting this challenge (e.g., Ridley, Mendoza, Kanitz, Angermeier, \& Zenk, 1994; Sodowsky, Taffe, Gutkin, \& Wise, 1994; Sue \& Sue, 2003). Although the call for increased therapist competence in working with ethnic and cultural groups predated Sue et al. (1992), it can be argued that their work initiated the most widely used standard for conceptualizing and investigating multicultural therapist competence. More specifically, Sue et al. (1992; Sue \& Sue, 2003) suggested that therapists and counselors need to attend to three main areas to appropriately serve diverse client populations: (a) knowledge-about the worldview and culture of their clients; (b) awareness-of their own culture and values and any biases and assumptions regarding the clients' ethnic or cultural group; and (c) skills-therapeutic actions and interventions that are relevant and appropriate for working with diverse clients.

\section{Knowledge}

MedFTs should be familiar with several key knowledge areas related to childhood cancer. These areas include prevalence rates, types of childhood cancer, treatments, and prognosis. In addition, MedFTs should have knowledge about the development and impact of serious illness on the family system. As an introduction to the topic, national statistics have indicated that childhood cancers account for $0.03 \%$ of all cancers diagnosed, with approximately 9,200 children younger than 15 newly diagnosed in 2004 (American Cancer Society, 2004). Although this translates to a yearly incidence rate of 1 in 6,500 children, when combined with the number of children receiving ongoing treatment, there are thousands of children and families coping with childhood cancer at any given point in time.

Despite medical advances in treatment, cancer is the leading cause of death in children younger than 15 (American 
Cancer Society, 2004). These advances in medicine have improved the survival rate to nearly $78 \% 5$ years after diagnosis. The most common type of childhood cancer is leukemia, and it accounts for $25 \%$ of cases, with acute lymphoblastic leukemia being the most common leukemia type (Hewitt, Weiner, \& Simone, 2003). Other common childhood cancers include tumors of the central nervous system, lymphomas, carcinomas, germ cell tumors, soft tissue sarcomas, sympathetic and allied nervous system tumors, renal tumors, retinoblastoma, and hepatic tumors (Hewitt et al., 2003).

It is important for MedFTs to be aware that childhood cancer is less common than cancers in adulthood (Brigham \& Children's Hospital, 2005); therefore, treatment for childhood cancer is limited to specialized medical centers with doctors who focus on pediatric oncology (Woznick \& Goodheart, 2002). Consequently, many families, especially rural families, must travel great distances to receive appropriate treatment, thereby experiencing considerable financial costs and emotional strain. Coupled with the trying nature of cancer treatment, travel means that families often have to leave their support networks of relatives and friends to help their child. Additional challenges are experienced as families are faced with decisions about starting conventional treatment or participating in clinical trials. This process is further complicated by the practical need to cover the costs of expensive treatments, which may require parents to investigate complex insurance plans or public assistance programs.

When working with these families, MedFTs will need to help families navigate these difficult decisions while being simultaneously charged with assisting children and parents to adapt to their cultural role as patient, member of the treatment team, and tenant (for those who maintain the hospital as their primary residence). Clearly, therapists must have knowledge regarding the layout and language of the hospital to help families understand what they are facing. This may translate into the therapist's physically accompanying a family to appointments, collaborating with hospital staff, or serving as a liaison between the parents and medical staff to ensure that the needs of all parties are understood.

Childhood cancer is a non-normative life event and an unnatural disaster in a family's development (Woznick \& Goodheart, 2002). Consequently, families must discover how to manage the inherent challenges without a great deal of societal guidance because of its uncommon occurrence. Parents are confronted with the possibility that their child's death may precede their own, a clear divergence from the expectations of the typical or normal family life cycle (McGoldrick \& Walsh, 1999). Other common but extremely intense emotional responses for parents include feelings of denial, fear, anger, and confusion.

Cancer treatment can have pervasive effects on a child's development not only emotionally but physically. Depending on the type of treatment the child is receiving, the child may experience developmental setbacks including slowed speech development, impeded progress with motor skills, and delayed social skills because of the isolation caused by hospitalization (Lingnell \& Dunn, 1999; Woznick \& Goodheart, 2002). Therapists should be knowledgeable about developmental milestones issues to help parents and hospital personnel provide the child opportunities for understanding and coping with developmental setbacks.

The knowledgeable therapist recognizes not only the toll that cancer takes on the parents and afflicted child, but also the impact the illness has on siblings, grandparents, extended family, and friends (Adams \& Deveau, 1984; Woznick \& Goodheart, 2002). Therapists need to make themselves aware of family members' common responses to interpret these reactions accurately without pathologizing certain 
behaviors or emotions. For example, siblings often become jealous of the sick child because all the parents' attention and energy is focused on getting the sick child better. Siblings can also have fears of catching the disease or may feel that they caused the illness in some fashion (Adams \& Deveau, 1984; Woznick \& Goodheart, 2002; for an in-depth review of sibling experiences, see Wilkins \& Woodgate, 2005).

\section{Awareness}

A competent therapist is aware of her or his own biases and assumptions regarding a specific group or culture so that these do not unduly and negatively influence therapy (Sue et al., 1992; Sue \& Sue, 2003). In our estimation, therapists need to monitor themselves in reference to two main awareness-related challenges to effectively serve families facing childhood cancer: self-oftherapist and the medical environment.

\section{Self-of-Therapist Challenges}

Among the chief internal struggles that therapists encounter in working with this group is the task of becoming aware of one's beliefs about illness, especially an illness that afflicts children. It is important for therapists to explore and evaluate their religious and spiritual beliefs regarding critically ill and dying children. By exploring their personal beliefs about these subjects with careful contemplation and/or discussions with colleagues, religious leaders, and others, therapists open space for families to explore their own beliefs regarding the illness and/or death. Other internal struggles might include feeling sorry for the family, fear of its happening to one's own child, and relief that it is not one's child (often accompanied by feelings of guilt). The sheer demand of working with this population requires that therapists monitor themselves for emotional burnout. In this regard, it is especially important that therapists consult with peers and engage in regular self-care activities.

\section{Medical Setting Challenges}

External assumptions and biases for the therapist to consider primarily center around working in a hospital setting. Specifically, the therapist must be aware of biases and assumptions about working in the hospital setting, defining new rules for confidentiality, and collaborating with medical personnel. To fully address the awareness component of cultural competence, the therapist needs to explore his or her own stereotypes about medical settings, people in hospitals, and work in hospitals.

The setting-based challenge of maintaining confidentiality can prove to be among the most difficult to address for family therapists beginning to work in hospitals. As a profession, therapists have certain views and ethical stances on confidentiality that are designed to protect clients against the inappropriate sharing of personal information. Although it is important to maintain client privacy, a strict interpretation of the client- or patient-therapist working relationship to the exclusion of the rest of the treatment team can often be disadvantageous. For example, in a hospital setting, therapists work with a team of doctors and nurses who often require general assessments and ongoing updates about the family to facilitate better care and consideration (McDaniel, Hepworth, \& Doherty, 1992). Second, as a general rule, hospital policies require that visits by specialists be documented in the patient's chart. Because this would include the assigned MedFT, clinical notes would need to be recorded as part of the patient's chart rather than in a separate document. For a traditionally trained therapist, it may be difficult to negotiate this matter because even when the family's records are considered confidential, they are certainly not as private as they would be in the more typical scenario of a locked filing cabinet.

A final setting-based assumption or bias for MedFTs to overcome is related to 
collaboration with the medical staff. This can be problematic for therapists if they hold, justifiably or not, an assumption that doctors, nurses, and hospital administration have a generally low level of concern for the patient's and family's emotional health. Appropriately, the medical staff's primary concern is saving the patient's life, which may facilitate an inattention to the client family's wellbeing in other areas. Some problems can be corrected and avoided, whereas some aspects of this particular cultural practice can only be dealt with if the therapist assumes the role of an intermediary between family and the medical staff.

\section{Skills}

The skills necessary for treating this population are guided by the type of cancer the child has and the family's specific needs. Presented here are some basic areas for assessment and some general interventions meant to be beneficial to families.

\section{Assessment}

A starting point for therapists working with this population is to obtain information concerning the child's specific type of cancer. The types of treatment the child faces will have a major impact on the child's emotional and physical well-being and on the family's experience of the illness. Beyond tailoring therapy to the specific illness, competent therapists assess the family, their belief system, their level of functioning, and their resources for support. McDaniel et al. (1992) recommended seven main topics to assess with families facing chronic illnesses in children. Corresponding questions are designed to assess the areas of (a) family beliefs about the illness, (b) triangles in the family related to the illness, (c) the impact on other relationships, (d) how siblings are functioning, (e) the developmental issues experienced by the child versus illness-related difficulties, (f) the family's relation to the medical team, and $(\mathrm{g})$ the family's level of support from their social network (McDaniel et al., 1992). Addressing these topics allows the therapist to view the illness in the context of a specific family and highlights areas in which intervention is needed.

A proficient therapist works within the culture of childhood cancer and focuses on collaboration with hospital personnel. Functioning as an intermediary, MedFTs can highlight key treatment issues with which the family is struggling, allowing the medical team to tailor its approach in a more sensitive manner. MedFTs must be innovative in both interventions and the way in which they are delivered. Children with cancer, especially when hospitalized, often express feelings related to loss of control, fear, pain, anger, and frustration (Adams \& Deveau, 1984; Lingnell \& Dunn, 1999; Woznick \& Goodheart, 2002). Incorporating play into therapy provides the child with another verbal or nonverbal way to communicate his or her thoughts and feelings (Gil, 1994). Play can also be used to work through terrifying situations and to bring the family together in a collective activity, through the use of puppet play, family group sand play, and art projects. Parents of children with cancer often combat feelings of helplessness that may be intensified in the hospital. By facilitating play between the child and parent(s), the therapist is promoting healthy relational interaction that will benefit the relationship in and out of the hospital (Lingnell \& Dunn, 1999). Taken one step further, play can include siblings, grandparents, and other family members to enhance those relationships as well.

Skills for working with adults in the family focus more on the experience of emotion and the provision of both support and parenting assistance. Specific skill or intervention areas include the ability to dialogue about spiritual issues, express compassion, facilitate client emotional expression, and provide reassurance and safety without judging. Behavioral-based parent training techniques can also prove beneficial for 
parents of children with cancer. A therapist skilled in creating behavior checklists, rule and reward charts, and other behavioral monitoring devices will serve the parents effectively as parents express frustration and confusion about disciplining their sick child and creating fairness between siblings (Woznick \& Goodheart, 2002).

In summary, although numerous studies and conceptual papers have addressed adjustment and coping issues surrounding chronic childhood illnesses (e.g., Cohen, Friedrich, Jaworski, Copeland, \& Pendergrass, 1994; Hoekstra-Weebers, Jaspers, Kamps, \& Klip, 2001; Lutz, 2001; Robinson et al., 2005; Schmidt, Petersen, \& Bullinger, 2003; Varni, Katz, Colegrove, \& Dolgin, 1996; Wallander \& Varni, 1998), very few have focused on the experiences and views of those adopted into the culture of cancer. As an exception, Robinson et al. (2005) examined the experiences of family members facing childhood cancer. This study adds to the work done by Robinson et al. by including the experiences and perceptions of the treatment team members because, as we propose, the treatment team becomes part of the culture of pediatric cancer treatment. Within the growing field of medical family therapy, Rolland (1994) and McDaniel et al. (1992) have included discussions of issues concerning chronic childhood illnesses, but information specific to childhood cancer is sparse. Prompted by the scarcity of empirical research and our own investment in the topic, we undertook this study to learn and better understand the culture of childhood cancer by investigating the experiences of pediatric oncology team members (medical staff and medical family therapists).

\section{METHOD}

\section{Participant and Clinic Description}

Participants in this study were identified because of their role as staff members in a pediatric oncology clinic. These individuals included doctors, nurses, support staff, chaplains, child life specialists, and MedFTs as members of a collaborative team treating children with cancer and their families. Ten members of the treatment team were asked to participate in the study, and nine questionnaires were completed and returned. Respondents included 1 doctor, 2 nurses, 2 child life specialists, a chaplain, a support staff, and 2 MedFTs.

The pediatric oncology clinic is located inside a children's hospital in the southwestern United States. The location of the clinic allows for increased contact between all members of the oncology treatment team (those in the clinic and those based in the hospital). Children come to the clinic for routine check-ups, chemotherapy, and any other outpatient treatment. The clinic also serves as a starting point for a hospitalization if children require more extensive treatments or when they are too ill to be at home. The children's hospital is one of two hospitals in the area, servicing a moderately sized city and large rural area that surrounds it (spanning several hundred square miles). As such, many of the patients and their family members must travel significant distances to receive ongoing treatment.

\section{Procedures}

Each participant was informed of the nature of the research and asked to sign a consent form. Participants were given questions in paper-and-pencil format in an effort to accommodate their schedules and to protect their confidentiality. On completion, participants returned their completed questionnaires and consent forms anonymously via mail.

\section{Measure}

We created eight open-ended questions in an effort to explore the area of culturally competent therapy in relation to pediatric cancer treatment. Questions included, "Describe, to the best of your ability, the major changes that take place for the family when a child is diagnosed with cancer," 
"Can you speak of the 'culture' of pediatric cancer (e.g., time spent in hospital, major medical procedures, bonds with other childhood cancer families)?" and "What would you want a family therapist who works with children and families facing childhood cancer to know?" A complete list of questions is included in the Appendix.

\section{Analysis}

This study can best be described as a qualitative description, as submitted by Sandelowski (2000), but we used the guidelines for analyzing data set forth by Moustakas (1994) to identify the themes that emerged. Once questionnaires were received, they were read by Amanda Douglas Harrington, who identified significant statements from each participant regarding his or her experiences of the phenomenon of pediatric cancer treatment. She then created a textural description from those statements and themes drawn from these textural descriptions. Finally, she wrote a description of the experience of being on a pediatric cancer treatment team and from that description constructed the overarching essence of the experience. We used extensive methods to increase the credibility, transferability, dependability, and confirmability (analogous to reliability and validity in quantitative studies) of the analysis. These methods included confirming the results with participants (a process called member checking) and using thick descriptions, peer debriefing, and auditors (Lincoln \& Guba, 1985).

\section{RESULTS}

We identified two themes in the textural description: the culture of change and significant relationships. Along with these themes, we created a qualitative description of medical family therapy on the basis of responses to the question about having MedFTs on the treatment team. Although all participants discussed both themes, we present them in order of prominence, based on how much the participants wrote about each area.

\section{Culture of Change}

According to participants, families and treatment teams encounter a tremendous initial change (in terms of individual and familial dynamics) at the point of diagnosis, coupled with an ongoing, continual need to adjust throughout the entire course of treatment. All 9 participants confirmed this concept, indicating the value of considering childhood cancer as a distinct culture within which dramatic change is a necessary and inevitable aspect.

The introduction to this culture of change included not only changes in routine, but changes in family interactions, income, and the ability to socialize with friends and family. One nurse stated,

Everything about their life changes. Their roles in their own family change. This child becomes the center of the family. Many times double-income families become single-income families. Children are homebound from school, which affects them socially. Other children [siblings] have to learn to deal with their new roles.

Related to the concept of change and the impact it has on a family, the physician wrote, "It's like the family unit is dropped off a 10-story building-it may or may not survive the fall. If there are weak areas (i.e., poverty, unmarried parents, single parents), there is more apt to be significant damage." Conversely, very strong families tend to strengthen. Another participant (the chaplain on the team) spoke of the culture of change in this way:

No aspect goes untouched or unaffected by such a diagnosis. Probably the biggest impact initially is marital, financial, and logistic (schedules, routines, activities of daily living). Each family, each individual makes this transition in varying degrees. In the course of this 
transition, holidays, vacations, school, careers, finances, socializing, religion, extended family, and immediate family all are impacted. Behavioral, emotional, and spiritual adjustments are made in every aspect of the patient's and family's life.

It is important to note that this change appeared to be all-encompassing as reflected in participants' responses. Families in this culture of cancer often talk about the difference in their family before and after diagnosis and the changes and transformation of their family.

\section{Significant Relationships}

The second major theme to emerge from the data was the development and maintenance of relationships throughout the course of treatment. All 9 participants wrote regarding the powerful relationships they developed with the children and their families. Participants spoke of being referred to by families as "members of the family," and all spoke of these relationships as being long term. It appears that these relationships do not exist just during treatment but rather endure long after treatment has ended. One nurse referred to these relationships as "everlasting." A MedFT on the treatment team stated,

This unique view into their family provides a very close relationship with the family in a way that others don't see, even their closest friends. We see them in their fear, their worry, their hope, and their sorrow. It's a privilege to walk with them as they make sense of this new entity of cancer in their lives.

As the last quote highlights, each participant seemed to speak of these relationships as valuable, deeply personal, and a privilege.

It is interesting to note that these relationships are not formed in the traditional manners of choice or birth. Instead, they are formed out of necessity for survival.
Several participants used the term security blanket in their discussion of their association with the family. Understandably, because the treatment team becomes part of the family's security and support system, family members miss these connections when they interact with the team less frequently. One MedFT wrote of an instance in which a family experienced anxiety over not seeing the treatment team as often:

I remember working with one mother of a patient right before they were going to go into maintenance. She had been coming almost weekly for appointments, and it was very much a part of her routine. She verbalized a sense of loss of not coming back each week. This experience showed me how important the relationship is between patients and staff. Their interactions make a stressful situation easier to bear.

As previously stated, these relationships are long lasting. Families have named babies after members of the treatment team and have asked the chaplain to perform their child's wedding. Pictures marking milestones in the families' lives are posted in the offices of the clinic, and families of both living and deceased children visit the clinic on a regular basis.

\section{MedFTs as an Essential Part of Treatment Team}

An additional valuable description of the role of MedFTs emerged from data analysis. More specifically, two subcategories of responses emerged within this description, including (a) the role of MedFTs in relieving the burden of other members of the treatment team and (b) the contributions of MedFTs in enhancing patient care.

Each of the 7 non-MedFT participants stated that the presence of an MedFT on the treatment team relieved the burden that other team members felt in terms of needing to address some of the systemic 
and emotional effects of pediatric cancer treatment. A nurse stated,

We aren't trained to deal with the emotional and psychological aspects of the families' needs. Family therapy has allowed me to go back to doing more of "my job" [knowing] that the patients' and families' needs are being met.

The physician on the team discussed the need for MedFTs this way: "Twenty 'I don't knows' in a row is demoralizing. [I'm] able to tell there is something wrong just by watching behavior but if I ask about it I wade into waters too deep to swim in." The chaplain's response also spoke to the relief he feels: "I have been relieved. Prior to the family therapists' addition to the treatment team, I was identified as the psychological resource. I am now able to give attention to my expertise."

The two MedFTs who participated expressed that they, too, saw the need for MedFTs on the treatment team and felt valuable to the team. One MedFT stated, "It seems like it relieves some of the [team's] burden from feeling the need to analyze and intervene in the family dynamics." The MedFT further stated, "I have realized that [the medical personnel] are very aware of the needs of the patients they work with and the families as well." It appears that although other team members are aware of the needs of families, they do not feel equipped to address those needs.

In reference to the second subcategory, team members also noted that MedFTs helped the team provide better care. One nurse stated, "Family therapy takes caring for the emotional person and family to the next level, offering solutions and support for families." A child life specialist said of MedFTs, "I believe the children relate well to a 'nonclinical' person. The families feel that they can open up to them and talk about their feelings and situations outside the medical realm." The other child life specialist said of her experience, "I have watched the therapists enable the children to address, deal with, and even resolve issues that would have otherwise gone untreated."

It appears that although not traditionally part of a pediatric oncology treatment team, MedFTs relieve the burden felt by other team members to provide holistic treatment to patients and families. This finding may highlight the uniqueness of pediatric cancer treatment and the desire to provide care for the entire family system. It seems, at least for this particular pediatric oncology team, that having a MedFT as a colleague allows members of the team to focus their expertise on patient medical care, knowing that the family's and patient's emotional and relational needs are being met.

\section{DISCUSSION AND LIMITATIONS}

In this exploration of the concept of a culture of cancer, we identified two important themes: the culture of change and significant relationships. In an allied fashion, an in-depth description of the need for MedFTs on the treatment team materialized. To more clearly conceptualize therapist competence in terms of this type of biocultural issue (Morris, 2000), we discuss the results in relation to the aforementioned dimensions of counseling-therapy competence (i.e., therapist knowledge, awareness, and skills).

\section{Knowledge}

As evidenced by the findings, therapists who intend to work in this setting should understand the culture of change that occurs for every family diagnosed with childhood cancer. Study participants mentioned specifically that family therapists working with this medical population should become knowledgeable about topics such as (a) chemotherapy and other medical treatments, (b) the financial burden encountered by most families in seeking treatment, and (c) the fact that the children and their families are strong and resilient. 
Each participant discussed the great change that occurs for families. Some types of change were mentioned by all participants, but each also identified different areas of change. This finding points to the amount of change faced by these families and the recommendation that a competent therapist should seek to assess the magnitude of that change in an effort to help facilitate coping.

\section{Awareness}

Although not identified as a significant theme, the response to the question concerning what MedFTs should know elicited answers from participants that were not necessarily skills based but rather were admonishments to be aware of the passion one might need to work with this population. A competent therapist should continually assess how she or he manages this type of work. Participants spoke of the toll that helping children with cancer and their families can have on an individual. Even with the inherent difficulties, several members of the team referred to this type of work as a "calling." This passion and calling may help to alleviate some of the toll this type of work has on therapists, but participants underscored the importance of self-awareness. One participant stated, "Self-awareness is essential. I do not believe anyone can 'know' this, but it is important that a therapist be willing to accompany an individual or family "through the valley."'

\section{Skills}

In terms of the skills necessary for working with children and families facing childhood cancer, the participants in the study focused on the therapist's ability to be open to each family's experience. One participant discussed how valuable hands-on experience is in working with children and their families with a cancer diagnosis, adding that theoretical and academic knowledge is not sufficient. The participant also stated that MedFTs need to be patient and have a skill set that allows them to simply sit with a family. It seems that being present (physically and emotionally) with these children and families and allowing them the space and freedom to experience their emotions is a valuable skill. It also seems important to validate the family's experience and not operate from the position of "expert" on how they should be reacting.

Although this study provides some helpful information for working with families facing a diagnosis of childhood cancer, it has limitations. One limitation is that cancer is not the only life-threatening illness faced by children, and not all of the results of this study will apply to other childhood illnesses. A second limitation is that we conducted the research by using paperand-pencil measures. Results may have been richer had an in-depth interview been conducted and transcribed. A third limitation is that the treatment team was a cohesive unit that is respectful of each discipline represented on the team. This may not be the mindset found in other pediatric oncology clinics in the United States. Also, one of the team members did not complete the survey. It would be interesting to know what this team member experienced and if it was similar to or different from the experiences of the other participants. Further research considering other childhood illnesses and research using more in-depth procedures could be beneficial in adding to the limited information available for working in this type of setting.

\section{CONCLUSION}

Therapists who desire to practice in a hospital setting have ample opportunity to help families who are facing a terrible time in life, such as having a child with cancer. In this article, we highlighted the need for therapists to see childhood cancer as its own culture requiring specific knowledge, awareness, and skills. Pediatric-oncology teams who serve these children and their families may consider 
the impact of the culture of change, relationships, and MedFTs as an important part of the treatment team. More teams like this may benefit from built-in mental health components with professionals such as MedFTs who understand family dynamics.

\section{REFERENCES}

Adams, D. W., \& Deveau, E. J. (1984). Coping with childhood cancer: Where do we go from here? (Rev. ed.). Hamilton, Ontario, Canada: Kinbridge.

American Cancer Society. (2004). Cancer statistics 2005. Retrieved November 13, 2005, from http://www.cancer.org/docroot/PRO/content/ PRO_1_1_Cancer_Statistics_2005_Presentation .asp

Brigham and Women's Hospital. (2005). How childhood cancers differ from adult cancers. Retrieved October 19, 2005, from https://healthlibrary.epnet.com/GetContent .aspx?token $=7 \mathrm{e} 9094 \mathrm{~F} 4-\mathrm{c} 284-4 \mathrm{~b} 3 \mathrm{a}-8 \mathrm{f} 7 \mathrm{c}-$ $867 \mathrm{fd} 12 \mathrm{~b} 36$ ee \&chunkiid $=30409$

Cohen, D. S., Friedrich, W. N., Jaworski, T. M., Copeland, D., \& Pendergrass, T. (1994). Pediatric cancer: Predicting sibling adjustment. Journal of Clinical Psychology, 50, 303-319.

Dowell, R. E. Jr., Copeland, D. R., \& van Eys, J. (Eds.). (1987). The child with cancer in the community. Springfield, IL: Charles C Thomas.

Gil, E. (1994). Play in family therapy. New York: Guilford Press.

Hewitt, M., Weiner, S. L., \& Simone, J. V. (Eds.). (2003). Childhood cancer survivorship: Improving care and quality of life. Washington, DC: National Academies Press.

Hoekstra-Weebers, J. E., Jaspers, J. P., Kamps, W. A., \& Klip, E. C. (2001). Psychological adaptation and social support of parents of pediatric cancer patients: A longitudinal study. Journal of Pediatric Psychology, 26, 225-235.

Kim, Y.-K., Bean, R. A., \& Harper, J. M. (2004). Do general treatment guidelines for Asian American families have applications to specific ethnic groups? The case of culturallycompetent therapy with Korean Americans. Journal of Marital and Family Therapy, 30, 359-372.

Lincoln, Y. S., \& Guba, E. G. (1985). Naturalistic inquiry. Beverly Hills, CA: Sage.

Lingnell, L., \& Dunn, L. (1999). Wholeness and healing for the hospitalized child. In D. S. Sweeney \& L. E. Homeyer (Eds.), Group play therapy: How to do it, how it works, whom it's best for (pp. 359-374). San Francisco: JosseyBass.

Lutz, G. (2001). Parental coping with the diagnosis of childhood cancer: Gender effects, dissimilarity within couples, and quality of life. Psycho-Oncology, 10, 325.

McDaniel, S. H., Hepworth, J., \& Doherty, W. J. (1992). Medical family therapy: A biopsychosocial approach to families with health prob. lems. New York: Basic Books.

McGoldrick, M., \& Walsh, F. (1999). Death and the family life cycle. In B. Carter \& M. McGoldrick (Eds.), The expanded family life cycle: Individual, family and social perspectives (pp. 185-201). Needham Heights, MA: Allyn \& Bacon.

Moore, R. J., \& Spiegel, D. (Eds.). (2004). Cancer, culture, and communication. New York: Kluwer Academic/Plenum Press.

Morris, D. B. (2000). Illness and culture in the postmodern age (Vol. 1). Los Angeles: University of California Press.

Moustakas, C. (1994). Phenomenological research methods. Thousand Oaks, CA: Sage.

Ridley, C. R., Mendoza, D. W., Kanitz, B. E., Angermeier, L., \& Zenk, R. (1994). Cultural sensitivity in multicultural counseling: A perceptual schema. Journal of Counseling Psychology, 41, 125-136.

Robinson, W. D., Carroll, J. S., \& Watson, W. L. (2005). Shared experience building around the family crucible of cancer. Families, Systems, \& Health, 23, 131-147.

Rolland, J. S. (1994). Working with illness: Clinicians' personal and interface issues. Family Systems Medicine, 12, 149-169.

Sandelowski, M. (2000). Whatever happened to qualitative description? Research in Nursing \& Health, 23, 334-340.

Schmidt, S., Petersen, C., \& Bullinger, M. (2003). Coping with chronic disease from the perspective of children and adolescents-A conceptual framework and its implications for participation. Child: Care, Health, and Development, 29, 63-75.

Sodowsky, G. R., Taffe, R. C., Gutkin, T. B., \& Wise, S. L. (1994). Development of the Multicultural Counseling Inventory: A selfreport measure of multicultural counseling competencies. Journal of Counseling Psy. chology, 41, 137-148.

Sue, D. W., Arredondo, P., \& McDavis, R. J. (1992). Multicultural competencies and standards: A call to the profession. Journal of Counseling and Development, 70, 477-483.

Sue, D. W., \& Sue, D. (2003). Counseling the 
culturally diverse: Theory and practice (4th ed.). New York: Wiley.

Varni, J. W., Katz, E. R., Colegrove, R., \& Dolgin, M. (1996). Family functioning predictors of adjustment in children with newly diagnosed cancer: A prospective analysis. Journal of Child Psychology and Psychiatry, 37, 321-328.

Wallander, J. L., \& Varni, J. W. (1998). Effects of pediatric chronic psychical disorders on child and family adjustment. Journal of
Child Psychology and Psychiatry and Allied Disciplines, 39, 29-46.

Wilkins, K. L., \& Woodgate, R. L. (2005). A review of qualitative research on the childhood cancer experience from the perspective of siblings: A need to give them a voice. Journal of Pediatric Oncology Nursing, 22, 305-319.

Woznick, L. A., \& Goodheart, C. D. (2002). Living with childhood cancer: A practical guide to help families cope. Washington, DC: American Psychological Association.

\section{Appendix A \\ Questionnaire}

1. What is your role on the pediatric oncology team? What is it like to be a in that setting?

2. What has been your experience with helping families and children facing childhood cancer? From diagnosis to remission-the process, including relationships developed with the families.

3. Describe, to the best of your ability, the major changes that take place for the family when a child is diagnosed with cancer (e.g., travel involved, meeting other families, changes in family routine, missed school, etc.).

4. What is your experience of death and dying when working with children and families facing childhood cancer?

5. Describe the benefits, if any, of having a family therapist on the treatment team.

6. What has your experience been since family therapists were added to the treatment team?

7. Can you speak of the "culture" of pediatric cancer (e.g., time spent in hospital, major medical procedures becoming routine, bonding with other families facing childhood cancer)?

8 . What would you want a family therapist who works with children and families facing childhood cancer to know? 